\title{
Food Habits and Physical Activity in Relation to the Nutritional Status of Adolescents in Urban and Rural Senior High Schools in Bogor
}

\author{
Mahamed Dol Ateye ${ }^{1}$, Ali Khomsan², Cesilia Meti Dwiriani² \\ ${ }^{1}$ Graduate School of IPB University, IPB University, Jl.Kamper, Dramaga Campus, Bogor, Indonesia \\ ${ }^{2}$ Department of Community Nutrition, Faculty of Human Ecology, IPB University, Jl.Kamper, Dramaga \\ Campus, Bogor, Indonesia \\ *Email of the corresponding author: erlangga259@yahoo.com
}

\begin{abstract}
The aim of this study was to know the food habits and physical activity in relation to the nutritional status of adolescents in urban and rural Senior high Schools in Bogor. The design of the research was a cross-sectional study, the number of subjects was 70 students from urban and rural. The data collection was carried out by using questionnaires, food recall 2x24 hour, physical activity recall 1x24 hour and anthropometry measurements. The results indicated that about $40 \%$ of urban adolescents were getting pocket money between Rp.20, 000-29,990 while $37.10 \%$ of rural adolescents were getting pocket money below Rp.10, 000 which shows the urban adolescents were getting more allowances than rural adolescents. Around $80.0 \%$ of total the urban adolescents have normal nutritional status while $57.1 \%$ of rural adolescents have normal nutritional status and $31.4 \%$ of rural adolescents were thin whereas $5.7 \%$ of urban adolescents were thin. The majority of the study participants have breakfast before leaving for school, also the majority of urban adolescents have more snack than rural adolescents. Generally, rural adolescents were physically active while most of the urban adolescents were physically inactive.
\end{abstract} Keywords : Breakfast, Snacking, Nutritional Status, Physical Activity

\section{INTRODUCTION}

Adolescences are one of the most exciting, however, it is a challenging period for the development of adolescents. Adolescents are periods of life that can occur between the ages of 12-21 years. Adolescences are the period of the tremendous psychologic, physiologic, and the transformation of the cognitive, during which the children become young adults. The regular growth patterns that characterize early childhood changes to one of the developments and, rapid growth affecting the psychosocial and physical aspects of the health (Larson, S.Stang, \& Leak, 2016). So the adolescents' physical activities and eating habits patterns are one of the important concerns in the presence of an accelerated nutrition transition.
Healthy food choices that combined with good regular physical activities can help to prevent a variety of many chronic diseases such as high blood pressure, obesity, diabetes, high blood cholesterol, heart disease, and certain cancers. One of the key features of the adolescents' eating patterns includes skipping breakfast, snacking, dieting, and adoption of specific diets. Also, Parents have the most influence on their children's' physical activity and dietary habits patterns, and most parents make a significant personal investment in their child's future. It was found that the qualities of diet and physical activity among adolescents are associated with the family income and mother's educational level (Al Sabbah et al. 2007). So one of the most important foods of the day is breakfast. Breakfast is the first eating occasion involving solid food or a beverage that 
occurred after waking. It is the first meal that appears to program the metabolism for the rest of the day. A team of researchers found that there may be some truth in the old saying "eat breakfast like a king, lunch like a prince and dinner like a pauper" may be the key to a healthy body and mind." It is a true that, the gap between dinner and breakfast is so high that an individual is really starving. So an individual tends to be deficient of all the nutrients in the morning, especially water-soluble nutrients that cannot be stored in the body. Breakfast should provide one-third of the daily nutritive needs(Yattinmani, 2012). Snacking plays an important role in the development of overweight and obesity, yet little is known about the context of snacking in adolescents or how snacking may influence other dietary habits, like meal skipping. Also snacking associated with undesirable health outcomes and dietary patterns. Since children and adolescents select snacks based on taste over nutrition, and more often choose salty, crunchy foods as snacks over healthier alternatives. Whereas the previous research indicated that snacking among children and adolescents occur most often in the afternoon and at home, information about the specific contexts in which adolescents snack (e.g. while doing homework or working, while watching television) is lacking (Ullery, Lee, \& Dalman, 2015). In the past few decades, physical activity patterns in adolescents have changed as a result of increased television watching, spending much time at a computer, and spending less time on physical activity in the schools and communities. Also, adolescences are characterized by biological, physical, psychological and social changes, with potential direct impacts on daily activities. The urban areas and rural areas may be associated with two different lifestyles and environment characteristics may contribute to lower levels of physical activities and fitness in adolescents (Suliburska et al. 2012). The movements of peoples from rural areas to urban areas, generally, identified as urbanization, and it is a common phenomenon that is observed all over the world during the development process of a country.

So Indonesia is one of the countries that have experienced a rapid process of increased urbanization and that is similar to the trends about the world). Since the mid-1990s, the total number of Indonesia's, the rural population has begun to decline, and today more than half of Indonesia's overall population lives in the urban environment (Meng et al. 2013). An unhealthy lifestyle among adolescent people is a serious and often unnoticed problem. This applies to young people from all backgrounds, but often it seems adolescent people brought up in rural areas lead a healthier lifestyle compared to their peers in big cities. Adolescents, in big cities, have easier access to shopping malls, supermarkets, etc., which continually advertise unhealthy food and high-calorie products. Access to public transport does not incline them to take daily walks. On the other hand, rural adolescents have a problem with access to sports facilities and a lower financial status, which often limits access to healthy food and an active way of spending their spare time. It is well known that the ability to lead a healthy lifestyle depends on various environmental factors, such as the level of nutrition education, access to sports facilities, and food habits including breakfast habits, frequency snacking and eating habits (Suliburska et al. 2012). Therefore, this study aimed to know the food habits and physical activity in relation to the nutritional status of adolescents in urban and rural Senior high Schools in Bogor.

\section{METHODS AND MATERIAL}

\section{A. Design, Location, and Time}

This study was used in a cross-sectional design and the Location of the research was the two public high schools in Bogor, SMA Negeri 3 Bogor, Baranangsiang, East Bogor, Bogor city, and SMA 1 Leuwiliang, 
Leuwiliang, Bogor, West Java, Indonesia and the place of the research was selected purposively. The research was conducted from June to September 2019.

\section{B. Subjects and Sampling Procedures}

\section{Subjects}

The subjects of this study were the students of urban and rural senior high schools in Bogor. The subjects were grade $10^{\text {th }}, 11$ th and $12^{\text {th }}$ students as well as willing to participate in the study and their ages 10-19 years and having healthy bodies. Exclusion criteria were students who were absent or did not attend the school on the second day of the study and did not return back the questionnaires. The number of the subjects was calculated based on the prevalence of Indonesian adolescents with energy intakes of less than the minimum requirement $(<70 \% \mathrm{RDA})$, that of, $54.5 \%$ (Ministry of Health [Depkes] 2010) with a confidence interval of $95 \%$. The minimum sample size of the subjects was calculated by using the formula of Lemeshow et al. (1997), to get the minimum number of the subjects: Calculation of the number of the sample (n).

$$
\begin{aligned}
& n=\frac{\left(Z_{\frac{\alpha}{2}}\right)^{2} * p *(1-P) N}{d^{2}(N-1)+\left(Z_{\frac{\alpha}{2}}\right)^{2} * p(1-p)}= \\
& \mathrm{n}=\frac{(1.96)^{2} * 0.545 *(1-0.545) x 643}{0.11^{2}(643-1)+(1.96)^{2} * 0.545(1-0.545)}=69.74 \approx 70
\end{aligned}
$$

\section{Where}

$\mathrm{N}=$ Number of population in the two high schools in Bogor (643)

$\mathrm{p}=$ prevalence of adolescents with energy intakes $<$ $70 \%$ RDA (54.5\%)

$\mathrm{d}=$ marginal error $(11 \%)$

$\mathrm{Z}=$ confidence interval of $95 \%$ (1.96)

\section{Sampling Procedures}

The sampling frame was created based on the students of $10^{\text {th }}, 11^{\text {th }}$ and $12^{\text {th }}$ grades in two public High Schools in Bogor (SMA Negeri 3 Kota Bogor and SMA Negeri 1 Leuwiliang) and then Randomization was taken in each school to determine the number of the students.

\section{Types and Methods of Data Collection}

The types of data that were used in this study included the characteristics of the subject age, sex, and amount of pocket money), food habits (eating habits, breakfast habits, and snacking habits), 3) physical activity level using one day physical activity recall, 4) food recall for 2x24 hour, 5) Anthropometric characteristics (body weight) were obtained from direct measurements using digital scales and height was measured using a stature meter.

\section{Data processing and Analysis}

Data processing and analysis were done by Microsoft Excel 2013 and SPSS (Statistical Program for Social Science) computer version 16.0 for Windows 10. Also, WHO-Anthro plus ver.1.0.4 (WHO, 2007) was used for the calculation of the nutritional status of adolescents. The physical activity level of the subjects was calculated according to the Report of a Joint FAO/WHO/UNU Expert Consultation Rome, 17-24 October 2001 (WHO/FAO/UNU, 2001). Univariate analysis was carried out descriptively to describe the pocket money, age, eating habits, breakfast habits, and snacking habits. Also, Correlation analysis was used on the relationship between food habits and pocket money.

\section{RESULTS AND DISCUSSION}

\section{RESULTS}

\section{Characteristics of the Sample}

The characteristics of adolescents consist of age and pocket money. The distribution of adolescents based 
on the characteristics of the adolescents can be seen in table 1 and it indicated that the adolescents were aged between 10-19 years and classified into three groups (10-13 years, 14-16 years, and 17-19 years) and all of the participants were attending high school. The results of this study indicated that the ages of subjects were $65.7 \%$ and $94.3 \%$ and the ranges between $17-19$ years from the urban and rural adolescents, also about $34.3 \%$ and $5.7 \%$ of them, their ages between $14-16$ years of age respectively whereas none of the subjects were aged between the 10-13 years. The results of the daily pocket money of the subjects from the urban and rural showed that most of them are getting daily pocket money between Rp.10,000-19,990 (51.4\% and $42.9 \%)$ respectively, also around $40.0 \%$ and $14.3 \%$ from the urban and rural students' daily pocket money between Rp.20,000-29,990 whereas $8.6 \%$ and 5.7\% were getting above Rp.30,000. None of the urban students were not getting below RP.10,000 but 37.1\% of the rural students are getting daily pocket money that below RP.10,000 and this shows that the daily pocket money of the urban students was more than that of the rural students.

Table 1. Distribution of Students based on the Characteristics of adolescents

\begin{tabular}{|c|c|c|c|c|c|c|}
\hline \multirow{2}{*}{ Variables } & \multicolumn{2}{|c|}{ Urban } & \multicolumn{2}{|c|}{ Rural } & \multicolumn{2}{|c|}{ Total } \\
\hline & $\mathrm{n}$ & $\%$ & $\mathrm{n}$ & $\%$ & $\mathrm{n}$ & $\%$ \\
\hline \multicolumn{7}{|l|}{ Age (year) } \\
\hline$-14-16$ & 12 & 34.3 & 2 & 5.7 & 14 & 20.0 \\
\hline$-17-19$ & 23 & 65.7 & 33 & 94.3 & 56 & 80.0 \\
\hline \multicolumn{7}{|l|}{ Pocket money per day } \\
\hline - <Rp. 10,000 & 0 & 0.0 & 13 & 37.1 & 13 & 18.6 \\
\hline - Rp.10,000-19,990 & 18 & 51.4 & 15 & 42.9 & 33 & 47.1 \\
\hline - Rp.20,000-29,990 & 14 & 40.0 & 5 & 14.3 & 19 & 27.1 \\
\hline - >Rp.30,000 & 3 & 8.6 & 2 & 5.7 & 5 & 7.1 \\
\hline
\end{tabular}

\section{Eating Habits}

Eating habits might mirror ones' daily eating patterns and therefore the eating habits are formed since the first ages once youngsters were still in their parents' care. If youngsters have obsessed a good eating habit and it's maintained till they're adult, their nutritionary balances are easier to realize or achieve. So the eating habits of the adolescents represented in the table below. Table 2 Distribution of the students based on their eating habits. Based on the urban and rural respondents the results of this study indicated that $88.6 \%$ and $82.9 \%$ of the urban and rural subjects. Usually, they eat white rice respectively. About $40.0 \%$ and $51.4 \%$ of urban participants consume rice for 2 and 3 times a day whereas the rural participants consume about $42.9 \%$ and $45.7 \%$. Also, around $5.8 \%$ of urban and rural adolescents consumed more than 3 times a day and those who consume only one time in a day were 2.9 and $5.7 \%$ of urban and rural adolescents respectively. In fact, none of the respondents from the rural participants always don't have a soft drink when they are eating, while only $2.9 \%$ of urban respondents have a soft drink when having a meal. Form the results of $54.3 \%$ and $37.2 \%$ of the urban and rural subjects they hardly ever have soft drinks respectively and about $34.3 \%$ and $48.6 \%$ study attendees from the urban and rural subjects, they have never had any soft drink when they are eating a meal. 
Table 2. Distribution of the students based on their eating habits

\begin{tabular}{lrrrrrr}
\hline & \multicolumn{2}{c}{ Urban } & \multicolumn{2}{c}{ Rural } & \multicolumn{2}{c}{ Total } \\
\cline { 2 - 7 } Variables & $\mathrm{n}$ & \multicolumn{1}{c}{$\%$} & $\mathrm{n}$ & $\%$ & $\mathrm{n}$ & $\%$ \\
\hline Types of carbohydrate source foods & & & & & & \\
- Fried rice & 1 & 2.9 & 2 & 5.7 & 3 & 4.3 \\
- White rice & 31 & 88.6 & 29 & 82.9 & 60 & 85.7 \\
- Pasta & 1 & 2.9 & 0 & 0.0 & 1 & 1.4 \\
- Fried noodles & 0 & 0.0 & 3 & 8.6 & 3 & 4.3 \\
- Others & 2 & 5.7 & 1 & 2.9 & 3 & 4.3 \\
Eating frequency of rice per day & & & & & & \\
- 1 time a day & 1 & 2.9 & 2 & 5.7 & 3 & 4.3 \\
- 2 times a day & 14 & 40.0 & 15 & 42.9 & 29 & 41.4 \\
- 3 times a day & 18 & 51.4 & 16 & 45.7 & 34 & 48.6 \\
- >3 times a day & 2 & 5.7 & 2 & 5.7 & 4 & 5.7 \\
Eating rice with soft drinks & & & & & & \\
- Yes always & 1 & 2.9 & 0 & 0.0 & 1 & 1.4 \\
- yes sometimes & 3 & 8.6 & 5 & 14.3 & 8 & 11.4 \\
- Yes, rarely & 19 & 54.3 & 13 & 37.1 & 32 & 45.7 \\
- Never & 12 & 34.3 & 17 & 48.6 & 29 & 41.4 \\
\hline
\end{tabular}

\section{Breakfast Habits}

Breakfast eaters have higher daily intakes of micronutrients and are more likely to meet nutrient intake recommendations compared with breakfast skippers. Breakfast skipping also has been associated with increased snacking or higher intakes of high-fat snacks. Omitting breakfast was associated with omission of other meals by adolescents Breakfast consumption may positively benefit cognitive function, particularly memory; academic performance; school attendance rates; psychosocial function; and mood. From the results of this study, the breakfast habits of the adolescents from the urban and rural participants indicted in table 3 Distribution of the students based on their breakfast habits. As seen from table 3 the total of the study results indicated that most of the adolescents take their breakfast between 05:00-07:00 so the results of this study showed that $45.7 \%$ of the urban adolescents have breakfast between 05:00-06:00 whereas 54.30\% have breakfast between 06:00-07:00. Also, about $22.9 \%$ of urban and rural adolescents have breakfast between 06:00-07:00 and 05:00-06:00 respectively. About $11.4 \%$ and $5.7 \%$ of respondents have breakfast after 09:00 respectively. The other side of the results of this study stated that $60.0 \%$ and $45.7 \%$ from urban and rural adolescents always have breakfast before going to school respectively, however, $28.9 \%$ and $31.4 \%$ of respondents sometimes they have breakfast before leaving for school. About $5.7 \%$ and $14.3 \%$ of urban and rural respectively, they hardly ever have breakfast before going to school when in fact that $5.8 \%$ and $8.6 \%$ for both of the urban and rural respondents have no breakfast before the school. So the results of this study indicated the breakfast habits of the students were good, however, there are little differences between the breakfast habits of urban and rural adolescents. Also, the types of breakfast that most of the adolescents consume as indicated by the total breakfast types is white rice. The results of this study show that white rice is the staple food in Indonesia so based on the distribution of the student's majority, they consume white rice and all most same with that four times to other breakfast foods so that $65.7 \%$ and $57.1 \%$ of the respondents from urban and rural 
adolescents whereas $20.0 \%$ and $8.6 \%$ of urban and rural adolescents consume bread as a breakfast and around $8.6 \%$ and $14.3 \%$ of urban and rural adolescents consume fired rice, also about $2.9 \%$ and $14.3 \%$ they were consuming fried noodles, however, $2.9 \%$ and $5.7 \%$ of the urban and rural adolescents were consuming other types of breakfasts.

In fact, the rural adolescents the results directed that none of them drink in fruit juice and tea in breakfast while $11.4 \%$ and $5.8 \%$ of urban respondents drink fruit juice and tea in their breakfast time. About $22.9 \%$ and $20.0 \%$ of urban and rural participants have drink coffee in their breakfast time when in fact $60.0 \%$ and $80.0 \%$ of urban and rural adolescents have other drinks in their breakfast times. The outcomes of this study revealed that around $57.1 \%$ of the urban and rural respondents have their breakfast over six times a week or every day. About $14.3 \%$ of urban and rural adolescents have breakfast 4-5 times a week and 20.0\% of both urban and rural have breakfast over 2 times a week whereas $8.6 \%$ of the urban and rural subjects have less a week or one time or not at all. About $80.0 \%$ and $88.6 \%$ of those study respondents from urban and rural respectively, they have their breakfast at their home while $17.2 \%$ and $8.6 \%$ of them have their breakfast at school and when in fact $2.9 \%$ of both respondents of urban and rural have breakfast somewhere else than school and their homes. The concepts of believing that breakfast is very important than other meals were common or same from the urban and rural adolescents and $74.3 \%$ of them said that breakfasts are important when you are studying at school. Only about $17.1 \%$ of the respondents from urban and rural adolescents were believed that breakfast is important only not to become weak or tired when we are playing with our friends and 8.6\% of all study participants believed breakfast isn't important without any reasons. Around $71.10 \%$ and $8.60 \%$ of respondents their breakfast are prepared by mothers and fathers respectively and this shows that the majority of the mothers are the caretakers of their children.

Table 3. Distribution of the students based on their breakfast habits

\begin{tabular}{|c|c|c|c|c|c|c|}
\hline \multirow{2}{*}{ Variable } & \multicolumn{2}{|c|}{ Urban } & \multicolumn{2}{|c|}{ Rural } & \multicolumn{2}{|c|}{ Total } \\
\hline & $\mathrm{n}$ & $\%$ & $\mathrm{n}$ & $\%$ & $\mathrm{n}$ & $\%$ \\
\hline \multicolumn{7}{|l|}{ Breakfast Time } \\
\hline$-05.00-06.00$ & 16 & 45.7 & 8 & 22.9 & 24 & 34.3 \\
\hline$-06.00-07.00$ & 8 & 22.9 & 19 & 54.3 & 27 & 38.6 \\
\hline - 07:00-08:00 & 5 & 14.3 & 4 & 11.4 & 9 & 12.9 \\
\hline - 08:00-09:00 & 2 & 5.7 & 2 & 5.7 & 4 & 5.7 \\
\hline$->09.00$ & 4 & 11.4 & 2 & 5.7 & 6 & 8.6 \\
\hline \multicolumn{7}{|c|}{ Breakfast before the School } \\
\hline - Always & 21 & 60.0 & 16 & 45.7 & 37 & 52.9 \\
\hline - Sometimes & 10 & 28.6 & 11 & 31.4 & 21 & 30.0 \\
\hline - Never & 2 & 5.7 & 3 & 8.6 & 5 & 7.1 \\
\hline - Rarely & 2 & 5.7 & 5 & 14.3 & 7 & 10.0 \\
\hline \multicolumn{7}{|l|}{ Types of Breakfast } \\
\hline - Bread & 7 & 20.0 & 3 & 8.6 & 10 & 14.3 \\
\hline - White rice & 23 & 65.7 & 20 & 57.1 & 43 & 61.4 \\
\hline - Fried rice & 3 & 8.6 & 5 & 14.3 & 8 & 11.4 \\
\hline - Fried noodles & 1 & 2.9 & 5 & 14.3 & 6 & 8.6 \\
\hline - Others & 1 & 2.9 & 2 & 5.7 & 3 & 4.3 \\
\hline \multicolumn{7}{|c|}{ Drinks with the Breakfast } \\
\hline - Fruit juice & 4 & 11.4 & 0 & 0.0 & 4 & 5.7 \\
\hline - Tea & 2 & 5.7 & 0 & 0.0 & 2 & 2.9 \\
\hline - Coffee & 8 & 22.9 & 7 & 20.0 & 15 & 21.4 \\
\hline - Others & 21 & 60.0 & 28 & 80.0 & 49 & 70.0 \\
\hline
\end{tabular}


Table 3. Distribution of the students based on their breakfast habits (continued)

\begin{tabular}{lrrrrrr}
\hline \multirow{2}{*}{ Variable } & \multicolumn{2}{c}{ Urban } & \multicolumn{2}{c}{ Rural } & \multicolumn{2}{c}{ Total } \\
\cline { 2 - 7 } & $\mathrm{n}$ & \multicolumn{1}{c}{$\%$} & $\mathrm{n}$ & $\%$ & $\mathrm{n}$ & $\%$ \\
\hline Number of Breakfast in a Week & & & & & & \\
- 6x / week (every day) & 20 & 57.1 & 20 & 57.1 & 40 & 57.1 \\
- 4-5x / week & 5 & 14.3 & 5 & 14.3 & 10 & 14.3 \\
- 2-3x / week & 7 & 20.0 & 7 & 20.0 & 14 & 20.0 \\
- 1x / week & 3 & 8.6 & 3 & 8.6 & 6 & 8.6 \\
Breakfast Place & 0 & 0.0 & 0 & 0.0 & 0 & 0.0 \\
- At home & 28 & 80.0 & 31 & 88.6 & 59 & 84.3 \\
- At School & 6 & 17.1 & 3 & 8.6 & 9 & 12.9 \\
- Others & 1 & 2.9 & 1 & 2.9 & 2 & 2.9 \\
The concept of Breakfast & & & & & & \\
- not important & 3 & 8.6 & 3 & 8.6 & 6 & 8.6 \\
- Concentrate the studying & 26 & 74.3 & 26 & 74.3 & 52 & 74.3 \\
- Not to become weak & 6 & 17.1 & 6 & 17.1 & 12 & 17.1 \\
Breakfast Preparation at Home & & & & & & \\
- Mother & 27 & 77.1 & 27 & 77.1 & 54 & 77.1 \\
- Father & 3 & 8.6 & 3 & 8.6 & 6 & 8.6 \\
- Grandmother & 1 & 2.9 & 1 & 2.9 & 2 & 2.9 \\
- Maid & 2 & 5.7 & 2 & 5.7 & 4 & 5.7 \\
- Others & 2 & 5.7 & 2 & 5.7 & 4 & 5.7 \\
\hline
\end{tabular}

\section{Snacking Habits}

Snacks are usually eaten between meals such as midmorning, mid-afternoon and before bed, they are often purchased from wandering street vendors or restaurants. The distribution of students of frequency snacking is shown in table 4 below. Table 4 Distribution of the students based on their snacking habits, the results of this study indicated that there are differences between urban adolescents and rural adolescents from their snacking habits. About $48.6 \%$ of urban adolescents, always they have snacks whereas only $28.6 \%$ of rural adolescent always have snacks. Also sometimes $45.7 \%$ of urban adolescents. Frequently they have had a snack when in fact $28.6 \%$ of rural adolescents have snacks and it shows that most of the urban adolescents have more frequent snacking then rural adolescents. Around $42.9 \%$ of rural adolescents rarely consume snacks whereas $5.7 \%$ of the urban adolescents, rarely consume snacks. Also, it be can be said that this result is relating From the pocket money of the urban adolescents were different from rural participants as shown in table 9 , about $37.1 \%$ of rural adolescents. They get pocket money less than Rp.10, 000 and Around $48.60 \%$ and $42.80 \%$ of urban and rural adolescents, they consume snacks less than five times a week while only $5.7 \%$ of urban respondents have snacks less than 3 times a week, however, $37.1 \%$ of rural respondents have snacks less than 3 times a week which again shows that rural adolescents are less frequent snacking than urban adolescents because of their less pocket money that they are earning. Also, $20.0 \%$ and $2.9 \%$ of urban and rural adolescents have snacks more than 6 times a week. The majority of the respondents both urban and rural adolescents that are consuming soft drinks/ ice and snack/cake, about $37.1 \%$ and $42.9 \%$ and $40.0 \%$, and $42.9 \%$ and $40.0 \%$ respectively. So, in general, the results indicated most of the urban and rural 
adolescents the types of snacks that they consume at most are soft drink/ice and snack cakes.

Table 4. Distribution of the students based on their frequent snacking

\begin{tabular}{|c|c|c|c|c|c|c|}
\hline \multirow{2}{*}{ Variables } & \multicolumn{2}{|l|}{ Urban } & \multicolumn{2}{|c|}{ Rural } & \multicolumn{2}{|c|}{ Total } \\
\hline & $\mathrm{n}$ & $\%$ & $\mathrm{n}$ & $\%$ & $\mathrm{n}$ & $\%$ \\
\hline \multicolumn{7}{|c|}{ Snacking Frequency } \\
\hline - Yes, always & 17 & 48.6 & 10 & 28.6 & 27 & 38.6 \\
\hline - Sometimes & 16 & 45.7 & 10 & 28.6 & 26 & 37.1 \\
\hline - Rarely & 2 & 5.7 & 15 & 42.9 & 17 & 24.3 \\
\hline \multicolumn{7}{|c|}{ Number of snacks per week } \\
\hline$-<3 x$ / week & 2 & 5.7 & 13 & 37.1 & 15 & 21.4 \\
\hline - 3-5x / week & 17 & 48.6 & 15 & 42.9 & 32 & 45.7 \\
\hline$-6 x$ / week & 9 & 25.7 & 6 & 17.1 & 15 & 21.4 \\
\hline - All the week & 7 & 20.0 & 1 & 2.9 & 8 & 11.4 \\
\hline \multicolumn{7}{|c|}{ Types of snacks that consume in the most } \\
\hline - Soft drinks/ ice & 13 & 37.1 & 15 & 42.9 & 28 & 40.0 \\
\hline - Cream & 7 & 20.0 & 6 & 17.1 & 13 & 18.6 \\
\hline - cake & 15 & 42.9 & 14 & 40.0 & 29 & 41.4 \\
\hline
\end{tabular}

\section{Pocket Money Managements}

Making smart financial decisions and managing cash well is not only a good habit to learn but it also contributes to future financial success. Since students are considered as the backbone of any country, to equip themselves both physically and mentally is essential for the strong foundation of a great nation tomorrow as well as that has a healthier nutritional status. Based on the distribution of the students' characteristics in their behavior of pocket money management is explained the following table 5 . As seen from the results all most of the adolescents live with their families, About $97.1 \%$ and $94.3 \%$ of the study participants from urban and rural adolescents are living with them (fathers and mothers) or (families). Around $77.1 \%$ of rural adolescents of which (34.3\% of Male and $42.9 \%$ of Female) they get pocket money less than Rp.500, 000 per month. Also, $48.6 \%$ of urban adolescents of which (31.4\% of Male and $17.1 \%$ of Female) they get pocket money less than Rp.500, 000 per month. The results of the study also showed that
$40.0 \%$ and $14.3 \%$ of urban and rural adolescents, they get pocket money between Rp.500, 000-Rp.1000, 000 respectively. Whereas only $5.7 \%$ and $2.9 \%$ of urban and rural respondents are getting pocket money between Rp.1, 000,000-2,000,000 respectively, also 5.7\% of urban and rural adolescents were getting above Rp.2000, 000 of pocket money.

About $82.9 \%$ of rural adolescents were getting in every day for their pocket money whereas $14.3 \%$ of them were getting in every two weeks and only $2.90 \%$ are getting per month. From the urban adolescents, about $57.1 \%$ are getting in every day for their pocket money when in fact $25.7 \%$ of them are getting in every week and $2.9 \%$ of them are getting in every two weeks. Also, $14.3 \%$ of the urban adolescents, they get in per month for their pocket money. Also from rural adolescents about $82.9 \%$, they get their allowances per day and about $14.3 \%$ and $2.9 \%$, they get per week and per month. On the other hand the majority of the study participants both urban and rural adolescents. They spent their pocket on foods. About $74.3 \%$ and $62.9 \%$ of urban and rural adolescents, they spent their pocket for 
only foods. Around $5.7 \%$ and $25.7 \%$ of urban and rural adolescents are saving their pocket money so this is indicating that rural adolescents are better than in urban for pocket money management. Only $2.9 \%$ of females from urban adolescents have used their pocket money to buy for Cosmetics whereas $11.4 \%$ and $5.7 \%$ of urban and rural participants have used for School supplies (e.g. pencils, folders, pens, and notebooks). In fact, the result of this study indicated that rural adolescents both male and female are better than urban adolescents for the behavior of pocket money management.

Table 5. Distribution of the students based on their pocket money managements

\begin{tabular}{|c|c|c|c|c|c|c|}
\hline \multirow{2}{*}{ Variables } & \multicolumn{2}{|l|}{ Urban } & \multicolumn{2}{|l|}{ Rural } & \multicolumn{2}{|l|}{ Total } \\
\hline & $\mathrm{n}$ & $\%$ & $\mathrm{n}$ & $\%$ & $\mathrm{n}$ & $\%$ \\
\hline \multicolumn{7}{|l|}{ The living arrangement } \\
\hline - My family & 34 & 97.1 & 33 & 94.3 & 67 & 95.7 \\
\hline - My father & 1 & 2.9 & 0 & 0.0 & 1 & 1.4 \\
\hline - My mother & 0 & 0.0 & 2 & 5.7 & 2 & 2.9 \\
\hline \multicolumn{7}{|c|}{ The pocket money/allowance (Rp) } \\
\hline$-<500,000$ & 17 & 48.6 & 27 & 77.1 & 44 & 62.9 \\
\hline - 500,000-1,000,000 & 14 & 40.0 & 5 & 14.3 & 19 & 27.1 \\
\hline - 1,000,000-2,000,000 & 2 & 5.7 & 1 & 2.9 & 3 & 4.3 \\
\hline - >2,000,000 & 2 & 5.7 & 2 & 5.7 & 4 & 5.7 \\
\hline \multicolumn{7}{|c|}{ The way of getting pocket money } \\
\hline - Every day & 20 & 57.1 & 29 & 82.9 & 49 & 70.0 \\
\hline - Every week & 9 & 25.7 & 5 & 14.3 & 14 & 20.0 \\
\hline - Every week & 1 & 2.9 & 0 & 0.0 & 1 & 1.4 \\
\hline - Every months & 5 & 14.3 & 1 & 2.9 & 6 & 8.6 \\
\hline \multicolumn{7}{|c|}{ How pocket money is usually spent } \\
\hline - Food and Drink & 26 & 74.3 & 22 & 62.9 & 48 & 68.6 \\
\hline - Savings & 2 & 5.7 & 9 & 25.7 & 11 & 15.7 \\
\hline - Cosmetics & 1 & 2.9 & 0 & 0.0 & 1 & 1.4 \\
\hline - School supplies & 4 & 11.4 & 2 & 5.7 & 6 & 8.6 \\
\hline - Others & 2 & 5.7 & 2 & 5.7 & 4 & 5.7 \\
\hline
\end{tabular}

\section{Correlation between Food habits and Pocket money}

Pearson's product-moment coefficient is the measurement of correlation and ranges (depending on the correlation) between +1 and $-1 .+1$ indicates the strongest positive correlation possible, and -1 indicates the strongest negative correlation possible. So, the closer the coefficient to either of these numbers the stronger the correlation of the data it represents. On this scale 0 indicates no correlation, hence values closer to zero highlights weaker/poorer correlation than those closer to $+1 /-1$. As seen in the results from the following table 6 a strong positive and negative correlation $(r=0.330$ and $r=-0.366)$ has been observed between the snacking habits and pocket money both in urban and rural adolescents' snacking. The results also showed a moderate correlation between eating 
habits and pocket money from both urban and rural adolescents. Also, the results from the rural area, it indicated that there is a weak/poor positive correlation between the fast foods and the pocket money while the urban respondents have indicated a moderate negative correlation between the fast foods and the pocket money.

Table 6. Correlation between food Habits and pocket Money

\begin{tabular}{lcc}
\hline \multirow{2}{*}{ Variables } & Urban \% & Rural \% \\
\cline { 2 - 3 } & $\begin{array}{l}\text { Pocket } \\
\text { Money }\end{array}$ & Pocket Money \\
\hline Eating habits & -0.125 & $-0.258^{* *}$ \\
$\begin{array}{l}\text { Breakfast } \\
\text { habits }\end{array}$ & 0.120 & -0.159 \\
$\begin{array}{l}\text { Snacking } \\
\text { habits }\end{array}$ & $0.330^{* *}$ & $-0.366^{* *}$ \\
Fast foods & -0.199 & 0.053 \\
\hline
\end{tabular}

\section{Nutritional Status of Subjects}

Nutritional status is a condition of the body as a result of food consumption and the use of nutrients. Anthropometry measurements can be used to determine nutritional status. Anthropometric indicators that can be used to measure nutritional status include age, weight, height, upper arm circumference, head circumference, hip circumference and thick fat under the skin (Brown, 2011). The indicators for measuring nutritional status used in this study were body weight and height. Measurement of nutritional status based on body mass index according to age $\left(\mathrm{BMI} / \mathrm{m}^{2}\right)$ is recommended as the best indicator for assessing the nutritional status of children aged over five years to 19 years as measured by the $\mathrm{Z}$ score(WHO, 2007). The distribution of the students based on their nutritional status. Based on table 8 , most of the urban adolescents the results showed that about $80.0 \%$ of urban respondents had a normal nutritional status.

This result also in line with the results of the study by (Ambarita, 2014) in elementary school children aged 9-13 years in Bogor city which shows that part of the nutritional status of primary school children is in Bogor City is classified as normal based on body mass index for age for $\mathrm{z}$-score (BAZ), 70.8\% of the research results indicated that they had normal nutritional status and $72.3 \%$ were female and $69.2 \%$ of male while the female respondents more than $3.1 \%$ from the male nutritional status. The finding of the rural adolescents indicated that about $57.1 \%$ had the normal nutritional status of which. There were differences between urban and rural adolescents. Around $31.4 \%$ of rural adolescents were thin whereas only $5.7 \%$ of urban adolescents were thin. Also from the pocket money of the urban and rural adolescents were the major factors that indicate the risk of malnutrition. In fact, about $14.3 \%$ of urban adolescents are overweighed whereas only $5.7 \%$ of rural adolescents are overweighed.

Table 7. Distribution of the students based on the nutritional status of adolescents

\begin{tabular}{|c|c|c|c|c|c|c|c|}
\hline \multirow{2}{*}{ BAZ } & \multirow{2}{*}{ Nutritional Status } & \multicolumn{2}{|c|}{ Urban } & \multicolumn{2}{|c|}{ Rural } & \multicolumn{2}{|c|}{ Total } \\
\hline & & $\mathrm{n}$ & $\%$ & $\mathrm{n}$ & $\%$ & $\mathrm{n}$ & $\%$ \\
\hline - $-3 \mathrm{SD} \leq \mathrm{Z} \leq-2 \mathrm{SD}$ & Thin & 2 & 5.7 & 11 & 31.4 & 13 & 18.6 \\
\hline - $-2 \mathrm{SD}<\mathrm{Z} \leq+1 \mathrm{SD}$ & Normal & 28 & 80.0 & 20 & 57.1 & 48 & 68.6 \\
\hline$\bullet+1 \mathrm{SD}<\mathrm{Z} \leq+2 \mathrm{SD}$ & Overweight & 5 & 14.3 & 2 & 5.7 & 7 & 10.0 \\
\hline$\cdot \mathrm{Z}>+2 \mathrm{SD}$ & Obesity & 0 & 0.0 & 2 & 5.7 & 2 & 2.9 \\
\hline & total & 35 & 100 & 35 & 100 & 70 & 100 \\
\hline
\end{tabular}

\section{Physical Activity of the Subjects}

The results of the physical activity level were obtained based on the first day of the data collection. The measurement of physical activity was carried out on 
the type of activity carried out by giving example and the length of time to do physical activity in a day.

Physical activity data were processed to obtain physical activity level (PAL) and is categorized as inactive (PAL <1.40), sedentary (1.40-1.69), active (1.7-1.99), and very active (2.00-2.40). As seen in the finding of the study there was a significant difference between urban and rural adolescents. The result of the physical activity of the urban and rural adolescents was different and it indicated that most of the rural participants both male and female had a more inactive physical with $54.3 \%$ of rural adolescents are inactive whereas $37.1 \%$ of urban adolescents were inactive.
According to the sedentary physical activity, about $34.3 \%$ of urban adolescents, their physical activity was low (sedentary) while $25.7 \%$ of rural adolescents were also sedentary life so the sedentary status indicated that rural adolescents were better than urban adolescent and this indicating some of the rural adolescents walk to the school. As a result, about $22.9 \%$ of urban adolescents indicated that their physical activity level was high (active) and $5.7 \%$ of them were very high (very active). Also from the rural adolescents, 5.7\% and $14.3 \%$ were active and very active. The most active students both urban and rural have involved playing of futsal, bicycle cycling and running.

Table 8. Distribution of the students based on the physical activity of adolescents

\begin{tabular}{llcccccc}
\hline \multirow{2}{*}{ Category } & \multirow{2}{*}{ PAL value } & \multicolumn{2}{c}{ Urban } & \multicolumn{2}{c}{ Rural } & \multicolumn{2}{c}{ Total } \\
\cline { 3 - 8 } & & $\mathrm{n}$ & $\%$ & $\mathrm{n}$ & $\%$ & $\mathrm{n}$ & $\%$ \\
\hline - Inactive & $<1.40$ & 13 & 37.1 & 19 & 54.3 & 32 & 45.7 \\
- Sedentary & $1.40-1.69$ & 12 & 34.3 & 9 & 25.7 & 21 & 30.0 \\
- Active & $1.7-1.99$ & 8 & 22.9 & 2 & 5.7 & 10 & 14.3 \\
- Very active & $2.00-2.40$ & 2 & 5.7 & 5 & 14.3 & 7 & 10.0 \\
& total & 35 & 100 & 35 & 100 & 70 & 100 \\
\hline
\end{tabular}

\section{Macronutrient Adequacy}

Macronutrients are needed in larger quantities (in gram range). They normally include water, carbohydrates, fat, and protein. Macronutrients (except water) are also called energy-providing nutrients. Energy is measured in calories and is essential for the body to grow, repair, and develop new tissues, conduct nerve impulses and regulates life process. The energy obtained by the body comes from carbohydrates, fats, proteins in food. Energy must be obtained regularly to meet energy needs for survival (Bendich, Bales, Temple, \& Editors, 2017). Excessive energy intake will be stored in the body as fat. The more fat stored, the more risk someone will be overweight and obese. According to (Boden et al.,
2015), overweight in adolescents is not only a consequence of health and psychology but will develop into a serious problem if experienced in the long term, such as type 2 diabetes mellitus and heart disease. Based on the distribution of adolescents' macronutrients consumption of school day and non-school day were discussed in the tables below. Lack of energy from food will cause someone to lack the energy to move, work, and do activities (Wijayanti, 2018). Lack of energy, in the long run, can cause a person to be thin and experiencing malnutrition. The finding of the study indicated that there were significant differences between urban and rural students, about $40.0 \%$ of rural adolescents, their energy intake in the school day below RDA\% $(<77)$ as compared the urban adolescents, whereas $20.0 \%$ of urban adolescents' energy intake in the school day were very less, this also indicated that 
the rural adolescents' energy intake in the school day was equal to two times the urban adolescents' energy intake in the school day. On the other hand, $28.6 \%$ and $25.7 \%$ of urban and rural adolescent have normal energy intake in the school day respectively, whereas $31.4 \%$ of urban adolescents have excessive energy intake in the school day, whereas $8.6 \%$ of rural adolescents have excessive energy intake in the school day, this result indicating that most of the rural adolescents have poor habits of getting sufficient of energy intake and also this reflects to their breakfast quality as it was low-quality food that has poor nutrients and poor diversity of other sources of the foods, as well as their pocket money as the rural adolescents have better behaviour of pocket money management.

Based on Table 8, the adequacy level of adolescents' carbohydrates, are generally, classified as less and enough and very high. The finding of the study showed that the adequacy of the carbohydrates from the urban participants was very high according to rural participants but the sufficient level of carbohydrates was the same in the school day. About $60.0 \%$ and $31.4 \%$ of urban and rural adolescents were very high in their adequacy level of carbohydrates respectively. Whereas about $37.1 \%$ and $8.6 \%$ of urban and rural adolescents were insufficient intakes in carbs during the school day and this shows that there is significant between the urban and rural adolescents respectively, their adequacy of carbs was insufficient. On the other hand, $31.4 \%$ of urban and rural adolescents have sufficient or normal in their carbohydrates intake in the school day. Carbohydrates are generally obtained from rice, rice vermicelli (rice noodles or bihun) and wheat flour. The lack of sufficient levels of carbohydrates in rural adolescents is that they don't consume enough food sources of carbohydrates such as tubers. Utilization of local food sourced from various tubers, sago, banana, breadfruit, pumpkin has been developed by making flour and it is expected that the various flour can be processed as a staple food substituting rice and flour as a source of carbohydrates (Kementan 2013). As seen from the study results, urban and rural adolescents there were significant differences between their macro and micronutrients intake and rural adolescents most indicated the most deficient of macro and micronutrients.

As indicated in 8 the conditions adolescents in rural areas, in general, the level of protein adequacy of the rural participants in this study mostly experienced a severe deficit or very less and less (37.1\% and $14.3 \%$ respectively). Lack of protein intake is caused by the low consumption of animal foods. This result is in line with the results of Ariningsih's (2002) research which shows that in low-income households in rural areas, the source of protein mainly comes from plant foods. The finding of the study showed that the protein intake of urban adolescents was very high (37.1\%) compared to the rural adolescents in the school day the results were different while the rural adolescents were insufficient in protein intake. Likewise, the sufficiency of protein adequacy of the urban and rural was the same in the school day (28.6\%). In addition, a severe deficit in the level of protein adequacy is also caused by the example of consuming only one type of protein, both vegetables such as tofu and tempeh, or animal protein such as eggs. The Balanced Nutrition Guidelines (BNG) recommends consuming 2-4 servings of food sources of animal and vegetable protein to meet daily protein needs (Kemenkes 2014). The majority of the urban and rural adolescents, the level of fat sufficiency on the average consumption was very high, and it was $71.4 \%$ and $54.3 \%$ of urban and rural adolescents respectively. Both urban and rural adolescents have a deficit but rural adolescents more significant to deficit below the RDA\% $(<20.0)$ intake, about $11.4 \%$ of urban and $20.0 \%$ of rural adolescents were a deficit in fat adequacy level respectively. About $14.3 \%$ and $25.7 \%$ of urban and rural adolescents have normal fat intake in their school day and this showed 
rural were better than urban adolescents. The adequacy of fat, mainly obtained from animal products and vegetable fat, which is derived from the oil in fried foods and coconut milk. This research is in line with the research of Marliyati et al. (2014) in elementary school children aged 7-9 years in rural areas showed that the majority $(80.6 \%)$ samples had fat intake in the greater than $20 \%$ of energy needs category.

Table 9. distribution of students based on their macronutrient intake

\begin{tabular}{llcccccc}
\hline Energy intake & & \multicolumn{2}{c}{ Urban } & \multicolumn{2}{c}{ Rural } & \multicolumn{2}{c}{ Rural } \\
\cline { 3 - 8 } RDA\% & Category & $\mathrm{n}$ & $\%$ & $\mathrm{n}$ & $\%$ & $\mathrm{n}$ & $\%$ \\
\hline$-<70$ & Very less & 5 & 14.3 & 5 & 14.3 & 10 & 14.3 \\
$-70-<100$ & Less & 6 & 17.1 & 7 & 20.0 & 13 & 18.6 \\
$-100-<130$ & Normal & 12 & 34.3 & 16 & 45.7 & 28 & 40.0 \\
$-\geq 130$ & Very high & 12 & 34.3 & 7 & 20.0 & 19 & 27.1 \\
Carbohydrate & & & & & & & \\
$-<50$ & Deficit & 4 & 11.4 & 6 & 17.1 & 10 & 14.3 \\
$-50-65$ & Normal & 10 & 28.6 & 9 & 25.7 & 19 & 27.1 \\
$->65$ & Very high & 21 & 60.0 & 20 & 57.1 & 41 & 58.6 \\
Protein & & & & & & & \\
$-<80$ & Very less & 6 & 17.1 & 6 & 17.1 & 12 & 17.1 \\
$-80-<100$ & less & 2 & 5.7 & 3 & 8.6 & 5 & 7.1 \\
$-100-<120$ & Normal & 11 & 31.4 & 12 & 34.3 & 23 & 32.9 \\
$-\geq 120$ & Very high & 16 & 45.7 & 14 & 40.0 & 30 & 42.9 \\
Fat & & & & & & & \\
$-<20$ & Deficit & 3 & 8.6 & 2 & 5.7 & 5 & 7.1 \\
$-20-30$ & Normal & 8 & 22.9 & 10 & 28.6 & 18 & 25.7 \\
$->30$ & Very high & 24 & 68.6 & 23 & 65.7 & 47 & 67.1 \\
\hline
\end{tabular}

\section{DISCUSSION}

The goal of this was to know food habits such as breakfast habits, snacking habits, and eating habits as well as physical activity in relation to the nutritional status of urban and rural adolescents. Based on the urban and rural respondents the results of this study indicated that $88.6 \%$ and $82.9 \%$ of the urban and rural subjects. Usually, they eat white rice respectively. About $40.0 \%$ and $51.4 \%$ of urban participants consume rice for 2 and 3 times a day whereas the rural participants consume about $42.9 \%$ and $45.7 \%$. Also, around $5.8 \%$ of urban and rural adolescents consumed more than 3 times a day and those who consume only one time in a day were 2.9 and $5.7 \%$ of urban and rural adolescents respectively. Also, this study in line with
(Kollataj, Sygit, Sygit, Karwat, \& Kollataj, 2011) Also, this study in line with (Kollataj et al. 2011) the eating, habits of adolescents were reported about $83.1 \%$ of the surveyed participants have the habit of eating their breakfast, before leaving a school. Almost $17 \%$ of the surveyed group denied drinking anything and eating breakfast before leaving for school. The difference between the mentioned fractions (percentages) was statistically significant. In the light of the conducted analysis, almost $3 / 5 \quad(62.2 \%)$ of the surveyed adolescents aged 9-13 years regularly take a light lunch to school. Altogether, $16.8 \%$ of them are in the rare habit of taking a light lunch $(6.4 \%)$ or take it irregularly (10.4\%). Almost 1/10 of respondents denied taking any light lunch to school. 
According to (Kromhout, Menotti, Kesteloot, \& Sans, 2002) the healthy behaviours of children and adolescents have been of interest to many researchers, particularly in recent years. So a proper lifestyle, which also includes the proper eating habits, which are the basis for the health status of adolescents, should be monitored to ensure adolescents' correct physical and psychological development. This is particularly important in rural areas. Therefore a rational diet is considered an important element of a healthy lifestyle. Many studies indicate the existence of numerous irregularities in the nutrition of children and adolescents, which results in their being overweight and obese. Breakfast is one of the integral parts of balanced dietary habits so besides regulating the feeling of hunger and satiety throughout the day, and it also meets the metabolic requirement that follows an overnight fast, therefore, the consumption of breakfast will improve the nutrient profiles by balancing intakes of the foods throughout the day. The general nutrient profiles are better by the increases in micronutrient intake and decreases in that of fats and sugar. The results of this study indicated that about $80.0 \%$ and $88.6 \%$ of urban and rural adolescents, they have their breakfast at their home while $17.2 \%$ and $8.6 \%$ of them have their breakfast at school and when in fact $2.9 \%$ of both respondents of urban and rural have breakfast somewhere else then school and their home.

Also, this research in line with (Yattinmani, 2012), the majority of rural (94.2\%) and urban (88.6\%) adolescents consumed breakfast whereas $5.8 \%$ of rural adolescents and $11.4 \%$ of urban adolescents skipped the consumption of breakfast. When compared between the localities, rural adolescent girls (93.36\%) and boys (95.06\%) be more than urban counterparts in breakfast consumption (82.20 and $92.56 \%$ of girls and boys) respectively. The finding of the present study indicated the coefficient of correlation ( $r$ ) of food habits and pocket money of urban and rural students is positive and negative. So a positive and negative low correlation was found in each relation. It may be concluded that there exists a significant effect between food habits and pocket money of the adolescents. The Correlation analysis indicated that the breakfast habits of the urban and rural adolescents were related to pocket money of the students and were moderate $(\mathrm{r}$ $=0.120$ and -0.159 ) respectively. However, the results revealed that significant correlation has been observed between snacking habits and pocket money of students and were $(r=0.330$ and $r=-0.366)$ which can be considered a high correlation or impact, it means whenever the students have more pocket money the more the students increases their frequency snacking. However, the factor which made this correlation between snacking habits and pocket money so high is that the students are preferring snacking than breakfast. According to (Antony \& Bhatti, 2015).

The pocket money of adolescents affects junk food consumption in children. though a negative correlation was seen and more than $60 \%$ of the participants between 16-18 years of age, they spend their entire pocket money on fast foods, therefore, among these adolescents $32.8 \%$ consumed fast foods four times a week, $28 \%$ three times, $25.2 \%$ had twice, and $14 \%$ once a week. Also, this study presented that $57.7 \%$ of the adolescents consumed junk food at home compared with $29.4 \%$ who had junk food from the school canteen, $40.9 \%$ at fast-food counters and $10.6 \%$ sharing from friends. According to the findings (Kaur \& Hegde, 2008), about $75 \%$ of the parents bought their children junk food from the restaurants and at least once a week compared to the about $23.5 \%$ of children who purchased junk food for themselves as these were willingly available on the school buildings.

\section{IV.CONCLUSION}

The sampling frame was created based on the students of $10^{\text {th }}, 11^{\text {th }}$ and $12^{\text {th }}$ grades in two public High Schools in Bogor (SMA Negeri 3 Kota Bogor and SMA Negeri 1 
Leuwiliang) and then Randomization was taken in each school to determine the number of the students. The results of the daily pocket money of the subjects from the urban and rural showed that most of them are getting daily pocket money between Rp.10,000-19,990 (51.4\% and $42.9 \%$ ) respectively, also around $40.0 \%$ and $14.3 \%$ from the urban and rural students' daily pocket money between Rp.20,000-29,990 whereas $8.6 \%$ and $5.7 \%$ were getting above Rp.30,000. Based on table 8 , most of the urban adolescents the results showed that about $80.0 \%$ of urban respondents had a normal nutritional status. The finding of the rural adolescents indicated that about $57.1 \%$ had the normal nutritional status of which. There were differences between urban and rural adolescents. Around $31.4 \%$ of rural adolescents were thin whereas only $5.7 \%$ of urban adolescents were thin. Also from the pocket money of the urban and rural adolescents were the major factors that indicate the risk of malnutrition. In fact, about $14.3 \%$ of urban adolescents are overweighed whereas only $5.7 \%$ of rural adolescents are overweighed.

\section{RECOMMENDATION}

To give short courses about nutrition education and counseling are very important to improve the adolescents' nutritional knowledge, especially counseling about the guidelines of balanced nutrition so that the food habits of the adolescents and can achieve adequate nutrients intake.

* To give short courses bout sport and exercise nutrition to improve physical activities during the school

* Parents should pay more attention to the child's food habits and get children accustomed to bringing food or drink supplies from home

Adolescents, who get more pocket money tend to spend it to buy street foods which often high in calorie but very poor in nutrient, so it would be better if the pocket money is over substituted by giving them a meal box for the breakfast or lunch to the school, and this is healthful as well as more balanced nutrients than the street foods

\section{VI.ACKNOWLEDGMENTS}

I greatly appreciate and thanked UC (University Consortium) for funding $1 / 3$ of this work, Also Without UC, my thesis work may not be finished on time.

\section{REFERENCES}

[1]. Al Sabbah, H., Vereecken, C., Kolsteren, P., Abdeen, Z., \& Maes, L. (2007). Food habits and physical activity patterns among Palestinian adolescents: Findings from the national study of Palestinian schoolchildren (HBSC-WBG2004). Public Health Nutrition, 10(7), 739-746. https://doi.org/10.1017/S1368980007665501

[2]. Ambarita, E. M. (2014). Association of dietary fiber and water intake with defecation pattern among elementary school students in Bogor City. Journal of Nutrition and Food, 9(1). https://doi.org/10.25182/jgp.2014.9.1.

[3]. Antony, M., \& Bhatti, R. K. (2015). Junk food consumption and knowledge about its ill effects among teenagers: a descriptive study. IJSR, 4(6), 1133-1136.

[4]. Bendich, A., Bales, C. W., Temple, N. J., \& Editors, G. A. B. (2017). Nutrition Guide for Physicians and Related Healthcare Professionals. (T. W. Norman J. Temple, George A. Bray, Ed.), Nutrition Guide for Physicians and Related Healthcare Professionals (Second Edi). (C) Springer International Publishing AG. https://doi.org/10.1007/978-3-319-49929-1

[5]. Boden, G., Homko, C., Barrero, C. A., Stein, T. P., Chen, X., Cheung, P., ... Merali, S. (2015). Excessive caloric intake acutely causes oxidative stress, GLUT4 carbonylation, and insulin 
resistance in healthy men. Science Translational Medicine, 7(304), 304re7-304re7.

[6]. Brown, J. (2011). Dietary Reference Intakes (DRIs): Recommended Intakes for Individuals, Vitamins Food and Nutrition Board, Institute of Medicine, National Academies. Fluoride. https://doi.org/10.1111/j.1753-

4887.2004.tb00011.x

[7]. Kaur, M., \& Hegde, A. M. (2008). Are we aware of what we are, we are what we eat-an epidemiological survey. International Journal of Clinical Pediatric Dentistry, 1(1), 13.

[8]. Kollataj, W., Sygit, K., Sygit, M., Karwat, I. D., \& Kollataj, B. (2011). Eating habits of children and adolescents from rural regions depending on gender, education, and economic status of parents. Annals of Agricultural and Environmental Medicine, 18(2).

[9]. Kromhout, D., Menotti, A., Kesteloot, H., \& Sans, S. (2002). Prevention of coronary heart disease by diet and lifestyle: evidence from prospective cross-cultural, cohort, and intervention studies. Circulation, 105(7), 893-898.

[10]. Larson, N., S.Stang, J., \& Leak, T. (2016). Nutrition in Adolescence. In J. and L. R. Kathleen, L.Mahan (Ed.), Krause's Food \& the Nutrition Care Process (14th editi, p. P.331). Saunders.

[11]. Meng, X., Manning, C., Shi, L., Effendi, T., Resosudarmo, B. P., Suryahadi, A., ... Yusrina, A. (2013). The Socio-economic and Health Status of Rural-Urban Migrants in Indonesia. The Great Migration,

(October). https://doi.org/10.4337/9781781000724.00018

[12]. Suliburska, J., Bogdański, P., Pupek-Musialik, D., Glód-Nawrocka, M., Krauss, H., \& Piatek, J. (2012). Analysis of lifestyle of young adults in the rural and urban areas. Annals of Agricultural and Environmental Medicine, 19(1), 135-139.

[13]. Ullery, B. W., Lee, J. T., \& Dalman, R. L. (2015). Snorkel/chimney and fenestrated endografts for complex abdominal aortic aneurysms. Journal of Cardiovascular Surgery, 56(5), 707-717. https://doi.org/10.1186/1479-Received

[14]. WHO/FAO/UNU. (2001). Report of a Joint WHO/FAO Expert Consultation: Diet, Nutrition, and the Prevention of Chronic Disease Geneva. Public Health Nutrition, 8(7A), 9291228. Retrieved from http://www.ncbi.nlm.nih.gov/pubmed/1627781 1

[15]. WHO. (2007). World Health Organization. AnthroPlus for Personal Computers. Manual: Software for assessing growth of the world' $s$ children. Geneva, 1-45. Retrieved from http://www.who.int/growthref/tools/en/

[16]. Wijayanti, N. (2018). the relationship between dietary habits, breakfast habits and nutritional status of Vocational High School student achievement in the city of Kediri. Scientific Journal of Health Sciences, 6 NO.1(1), 36-45. https://doi.org/10.1042/BST20180079

[17]. Yattinmani, N. M. (2012). Breakfast Behaviour and its Impact on Nutritional Status of Adolescents of Rural and Urban Dharwad Taluk. UAS, Dharwad: UAS, Dharwad.

\section{Cite this article as :}

Mahamed Dol Ateye, Ali Khomsan, Cesilia Meti Dwiriani, "Food Habits and Physical Activity in Relation to the Nutritional Status of Adolescents in Urban and Rural Senior High Schools in Bogor", International Journal of Scientific Research in Science and Technology (IJSRST), Online ISSN : 2395-602X, Print ISSN : 2395-6011, Volume 6 Issue 6, pp. 20-36, November-December 2019. Available at doi : https://doi.org/0.32628/IJSRST19667 Journal URL : http://ijsrst.com/IJSRST19667 